\title{
The Newtonian Model of the Smolensk Catastrophe
}

\author{
Józef Pawelec* \\ The European University in Warsaw, Warsaw, 03-199, Poland
}

\begin{tabular}{l} 
A R T I C L E I N F O \\
\hline Article history: \\
Received: 23 April, 2020 \\
Accepted: 02 September, 2020 \\
Online: 27 September, 2020 \\
\hline
\end{tabular}

Keywords:

Suspicious fog

Misleading radar

$3 D$ model of crash

\begin{abstract}
A B S T R A C T
The pre-reason of the Smolensk catastrophe was a dense fog. The pilots took three trials to find the proper way to airfield. Each case the tower communicated: you are on the curse and path. Pilots, however, resigned. In third critical trial the co-pilot prolonged the response second ring to 8 seconds and the engines could not already take the plane up. It collided with a thick tree and made an upside down. Next it crashed on the ground and left a bloody trace of merely $100 \mathrm{~m}$ long. This means that a mean acceleration at initial speed of $100 \mathrm{~m} / \mathrm{s}$ and linear braking reached $-50 \mathrm{~m} / \mathrm{s}^{2}$. The real values could be even higher as the peak slowdown is always higher the mean. The clue of the Smolensk crash was then a fog and high azimuth error of radar. If it was correct but the ceiling too low, the plane could lose the under-carriage but avoided the upside down and the bloody crash.
\end{abstract}

\section{Introduction}

The Smolensk catastrophe took 96 victims: the Polish chief political and military leaders including the current President Lech Kaczynski and the President on Exile - Richard Kaczorowski. The reasons of this tragic event are still under investigations. The Poland claims it was assassination [1]-[3], while the Russia rejects it [4]. So, our statements - although math-physically correct should be recognized as some hypothesis. The final verdict waits for an international legal process. The plane crashes in civil transport occur one per a million of flights and they are caused by the pilot faults, the engine failures or the foggy weather. It is obvious that Polish Side has chosen the best crew for this high rank visit: the high educated and experienced pilots, familiar with $\mathrm{Tu}-$ 154. They knew the airfield and speak Russian. Also, the plane has undergone to the major overhaul 2 years ago. So, the technical problems or the pilot faults seem to be unlikely.

\section{The Weather}

In UTC 10:40:52 of 10-th April 2010 at $2 \mathrm{~km}$ to the airport the crew was informed by the tower: you are in the curse and path! [3], [4]. The Tu-154 in that moment was $90 \mathrm{~m}$ over the local terrain but merely $30 \mathrm{~m}$ over the far airfield plane, Fig. 1 . The speed was $78 \mathrm{~m} / \mathrm{s}$ and the descent rate $-6.2 \mathrm{~m} / \mathrm{s}$. Hence, the proper level should be

$$
h_{\text {proper }}=\left(\frac{2000}{78}\right) * 6.2=160 \mathrm{~m}, h_{\text {choosen }}=30 \mathrm{~m}
$$

*Corresponding Author: Józef Pawelec; Email: k.kosmowski@wil.waw.pl
Moreover, the curse of flight was $\sim 8^{0}$ left the runway. It is defined by the airfield tower and the collision point to come. The direction error was more dangerous than the low level of flight because the last one causes usually the loss of the undercarriage, while the false direction results in dangerous collisions with trees or buildings. And Tu-154 just collided with a birch of $40 \mathrm{~cm}$ thick and has lost $\sim 6 \mathrm{~m}$ of the left wing! This caused the plane to upside down within several seconds and to crash in half-backside position $425 \mathrm{~m}$ before and $150 \mathrm{~m}$ aside the airfield in a hostile environment, Fig.1. We will show that the speed of hitting the ground could reach $100 \mathrm{~m} / \mathrm{s}$. The crater was also $\sim 100 \mathrm{~m}$ long. Hence, at linear braking the negative acceleration reached $-50 \mathrm{~m} / \mathrm{s}^{2}$. The real cases are always non-linear and bring higher values, so none could survive.

If there was no directional error, some accident could also take place, but it would surely draw less victims - if any - thanks to the braking action and normal position of plane.

So, we claim that main determining factors of the $\mathbf{T u}-154$ crash in Smolensk were the extremely foggy conditions and the high directional error of the radar reaching $-8^{0}$ !

The visibility along the horizon line was $\sim 300 \mathrm{~m}$, so in case of an obstruction there was a few seconds for an escape. In such conditions the Head Command was not entitled to give the permission for landing at all!

It is probably the historical precedence that the plane with President on board was taken down in dense fog with the radar of an angular inaccuracy reaching $\pm 8^{0}$. 


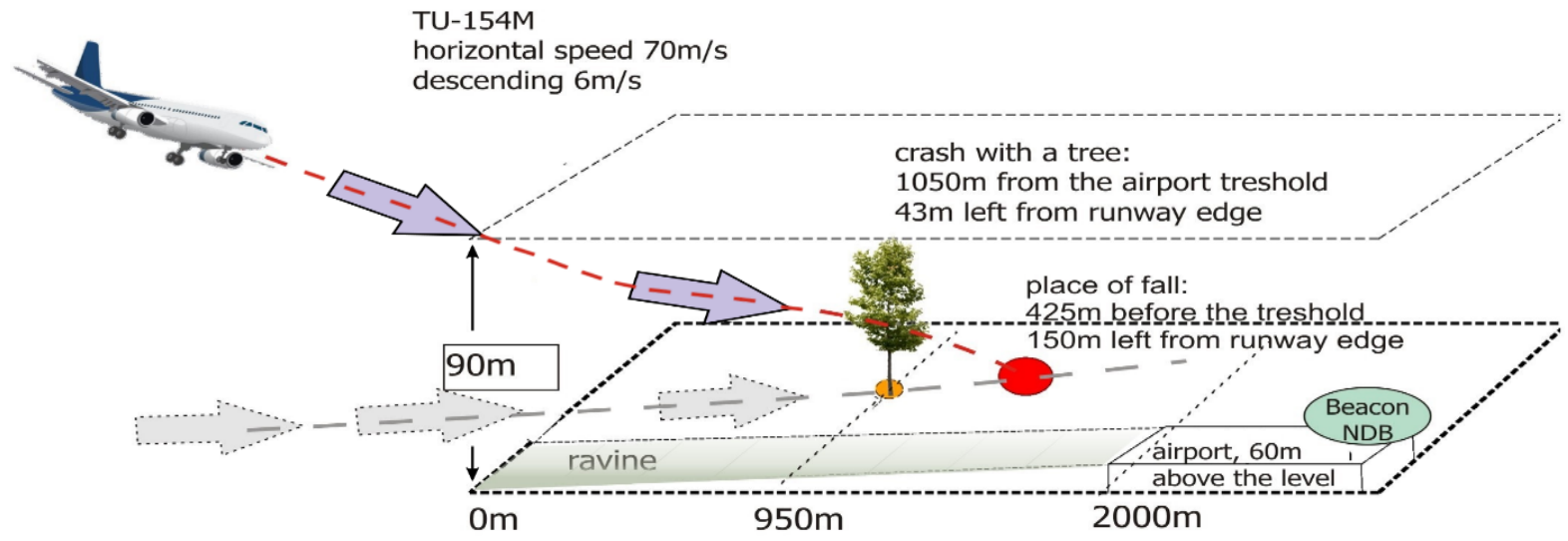

Figure 1: An illustration of the Tu-154 catastrophe: the plane flies much steep and much left the runway

The parts of crash have been dispersed over the area of $\sim 300 \times 300 \mathrm{~m}$. This gave rise to some suspicious theories of assassination. The question is, however, who and when arranged a plot and put an explosive material on the board? So, we will trust further on the physical basis. The mass of Tu-154 reached 90 ton and the landing speed approached $100 \mathrm{~m} / \mathrm{s}$ due to engines and gravity. If the collision is resilient, the reflection distance is given by eq. (2) [5], [6]

$$
h=v^{2} \sin (2 \alpha) / 2 g
$$

where $\mathrm{v}$ - the speed, $\alpha$ - angle to the ground, $\mathrm{g}$ - acceleration.

For $\mathrm{v}=100 \mathrm{~m} / \mathrm{s}$ and $\alpha=15^{0}$ this distance reaches $\mathrm{h} \approx 250 \mathrm{~m}$.

If the collision is not resilient, the body is crashed but the maximal distance of parts dispersion reaches the comparable or even higher values $( \pm)$.

For live beings the critical parameter is the negative acceleration. According to the witness reports the length of the landing crater reached $\sim 100 \mathrm{~m}$. The initial speed was also $\sim 100$ $\mathrm{m} / \mathrm{s}$ due to the engines and gravitation. Assuming linear decreasing of speed, we obtain the mean of $\sim 50 \mathrm{~m} / \mathrm{s}$ and the time to run over the crater $-2 \mathrm{~s}$. However, at the beginning the speed decreases much higher than in the end, so we will use the total time to run only $1 \mathrm{~s}$. Hence the maximal acceleration reached

$$
a=\frac{\Delta V}{\Delta t} \approx-100 \frac{m}{s}: 1 s=-100 \frac{m}{s^{2}} \approx-10 G
$$

The real values could be even greater, while $3 \mathrm{G}$ is already dangerous.

How these physical phenomena can be transferred onto the live body? The most sensitive is usually the heart. It can tolerate the acceleration up to $3 \mathrm{G}$. The level of $10 \mathrm{G}$ is usually the lethal one.

\section{Modelling of The Up-Side Down}

The up-side down turnover played the critical role in all the catastrophe. We will model it using the Newtonian's theory.
The most important role in this theory plays the transversal distribution of the masses $m_{i}$ along the wings line. If the mass $m_{\mathrm{i}}$ is at the distance $r_{i}$ from the centre of turning, then - in case of breakdown - the energy and movement increases proportionally to $m_{i} r_{i}^{2}$. We could observe such scenes during the war if a plane tears a part of its wing in a battle. Then, it spins down and crashes in blow of fire.

The Tu- 154 has lost one third of the wing in a crash with big tree $(40 \mathrm{~cm})$. This was the very dangerous disturbance. We should take into account that $90 \%$ of the plane masses are gathered in its very centre $( \pm 2 \mathrm{~m})$, so in case of loss of a distant part, the plane is turned very quickly by $\sim 180^{\circ}$. We will calculate this turn-over using the real data.

The inertial moments will be defined for two mass distributions: the linear and exponential one. Next, we will take a mean. Below, the eq. (4) defines the square of the linear inertial moment $k_{l}^{2}$, while eq.(5) - the exponential moment $k^{2} e_{e}$ [5], [6]

$k_{l}^{2}=\frac{1}{M} \sum_{i=14}^{0} m_{i} r_{i}^{2}=\frac{1}{45}\left(\begin{array}{c}4 * 14^{2}+8 * 10^{2}+ \\ 12 * 6^{2}+16 * 2^{2}+0\end{array}\right) \approx \frac{2100}{45}$

hence $k_{l} \approx \sqrt{\frac{2100}{45}} \approx 6.8 \mathrm{~m}$

The symbols used in eq. (4) mean:

$M$ - the half mass of the plane body [45000 kg =45 t],

$m_{i}-$ its digitalized part at the distance of $r_{i}$

$r_{i}$ - the arm from the middle of plane to $m_{i}$

$k$ - the resultant arm of inertia [m].

The similar expressions for the exponential distribution of the wing masses bring the following results

$$
k_{e}^{2}=\frac{1}{M} \sum_{i=14}^{0} m_{i} e^{-r_{i}}=\frac{1}{45}\left(\begin{array}{c}
4 e^{-14}+8 e^{-12}+ \\
16 e^{-2}+\cdots
\end{array}\right) \approx 0.53
$$

hence $k_{e} \approx 0.73 \mathrm{~m}$.

Finally, we have chosen the square mean between (4)-(5) $k_{l}=6.8 \mathrm{~m}, k_{e}=0.73 \mathrm{~m}$; hence, square mean $k \approx 2 \mathrm{~m}$. 


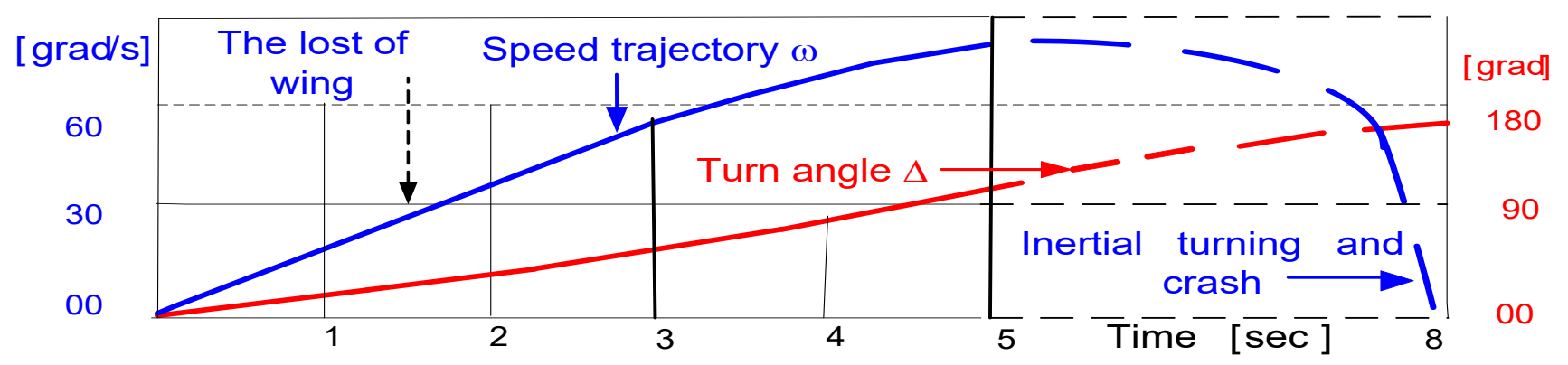

Figure 2: The simulated axial speed $\omega$ and the turn angle $\Delta$ of the Tu-154 plane after its collision with the tree vs. time

The angular frequency $\omega$ and the acceleration $\alpha$ of any rotation body is given by the following equations [5], [6]

$$
\omega=F r t / M k^{2}
$$

$\omega$ - the angular speed of a body [degrees/s], $t$ - the running time [s].

\section{The Axial Turning}

The force $F$, eq. (6), is the result of unbalance caused by the loss of a wing part and - next - the loss of total wing. We will take its mean as $10 \%$ of the gravitation force, $F=0.1 * M$. Hence, for the shortened wing of $r=13 \mathrm{~m}$ and the square of an inertial moment $k^{2}$ $=4 \mathrm{~m}^{2}$, we obtain the approximated equation for the orbital speed $\omega$ in the first seconds, see (6)

$$
\omega(t)=\left(\frac{F}{M}\right) *\left(\frac{r}{k^{2}}\right) t=0.1 *\left(\frac{13}{4}\right) t=0.33 t
$$

This means that in the first second the plane turns around by 0.33 of radian, i.e. $\sim 20^{\circ}$ !

One can observe in Fig.1 that a birch and the fall down points are distant away by $525 \mathrm{~m}$. The plane used to cover it $\sim 8 \mathrm{~s}$, Fig. 2 . So, the mean speed was $\sim 65 \mathrm{~m} / \mathrm{s}$ and the max value could easily reach $100 \mathrm{~m} / \mathrm{s}$.

The red line shows the plane angle $\Delta$ relative to the horizon. We can see it is near $180^{\circ}$.

\section{The Discussion}

The Russia accuses the Polish pilots for the crash [4]. This has no grounds. These pilots were the most experienced officers. They landed safely in extremely conditions, also on this same airfield and same plane and have made 3 trials preceding the crash! It is not excluded that a reason of the tragedy was an artificial fog and some falsification of the radar system without the knowledge given to the tower staff. No planes used this radar. The Putin's plane used modern ILS system.

The crashes in forests bring usually the fatal toll. Only in Poland there were two big ones: in Kabaty near Warsaw and in Miroslaviec. Nobody survived! The extensive literature on Tu-154 crash is given in [7-19].
In Smolensk crash, the large masses of Tu-154 were located in the very centre $( \pm 2 \mathrm{~m})$, while the strange force appeared much outside $(\sim 13 \mathrm{~m})$. These caused the plane to turn backside in $\sim 8 \mathrm{sec}$. and in next few seconds it crashed on the freeze woody ground without any control by the crew. As we have shown the speed obtained $\sim 100 \mathrm{~m} / \mathrm{s}$ due to the engines and the gravity.

Such a crash could be compared - within the energy domain $\left(10^{9} \mathrm{kgm}\right)$ - with the point collision of 4 trucks at a traffic circle, each of $22 \mathrm{t}$ and the speed of $180 \mathrm{~km} / \mathrm{h}$. Who can risk to stand inside such a circle?

Why the crashes in the air are so dangerous in comparison with the land crashes? This is because in the last case the cars have the support in the ground, while the planes are hanging in free space. If one engine is damaged, the pilot can use the power of the second one, but if the wing is damaged, especially its ending part, the pilot is helpless.

The second wing could not replace the first one, because its role is just contrary to the action of the first.

\section{Conclusions}

The math-physical model of the Smolensk catastrophe has been given. It takes into account the distribution of masses, the values of forces, their directions and the resulted movement of a plane in pseudo 3D space. This approach is based on the Newtonian theory. It explains while the plane has made an upside down and why it crashed on hundred parts over the area of $\pm 300 \mathrm{~m}$. This analysis suggests also the pre-reasons of the crash: the dense fog (artificial?), the radar having no valid certifications (?) and the tower staff not informed about (?) These charges should be investigated in the further legal process.

\section{Conflict of Interest}

The author declares no conflict of interest.

\section{Acknowledgment}

The author is obliged to phd $\mathrm{K}$. Kosmowski and $\mathrm{Mr}$ B. Grochowina for their valuable discussions and help in preparation the paper.

\section{References}

[1] J. Pawelec, "The Smolensk Catastrophe in the Light of Physics Lows", WORLDS4, London, July 30/31, 2019.

[2] J. Pawelec, "Misguidance under the Polish Tu-154 Crash", International Journal of Computers and Information Technology, September, 2018.

[3] The Ministry of Home Office, Poland, The Final Report of Tu-154 Crash, 
Warsaw, July 31, 2011.

[4] The Interstate Aviation Committee, The Final Report of Tu-154 Crash, Moscow, February 29, 2012.

[5] D. Halliday at al., Fundamentals of Physics, John Wiley and Sons 2000.

[6] M. Jeżewski, Physics, Gov. Science. Ed., Warsaw 1991.

[7] Polish Pilots Saw Crash Coming, BBC News, 16.04.10

[8] Smolensk Air Disaster ( Polish AF Tu-154 Crash), 2011

[9] Landing System Incompatibility Caused the Crash, 2012

[10] The Polish Pilots Asked for Russian Navigator, 2013

[11] N. Ojewska, Poland Polarized on Plane Crash, 2013

[12] P.Witakowski, Conferences on Smoleńsk Crash, 2013

[13] RiaNovosti: Polish Pilot was advised not to land, 2014

[14] The Tower Didn't Speak Eng., Rec. not landing, 2015

[15] Black Box Recording Made Public, TV-Novosti, 2015

[16] Apelblat M., British Experts Call for Future Inv.,.2015

[17] Poland to Russia over Withholding Wreckage, 2015

[18] Polish President Duda on Smolensk Crash, 30.11.2015

[19] Poland Re-open Investigations on Smolensk, 2016 